\title{
COMUNICAÇÃO
}

\section{EFEITO DA DENSIDADE POPULACIONAL DO PULGÃO-VERDE Schizaphis graminum (Rondani, 1852) (Hemiptera: Aphididae) NA ATIVIDADE ENZIMÁTICA EM PLANTAS DE TRIGO}

\author{
Effect of the population density of the greenbug Schizaphis graminum \\ (Rondani, 1852) (Hemiptera: Aphididae) on enzymatic activity on wheat plants
}

\begin{abstract}
Flávia Batista Gomes ${ }^{1}$, Custódio Donizete dos Santos ${ }^{2}$, Jair Campos de Moraes ${ }^{3}$, Marcio Marcos Goussain ${ }^{1}$
RESUMO

Verificou-se o efeito da densidade populacional do pulgão-verde Schizaphis graminum (RONDANI, 1852) em plantas de trigo (Triticum aestivum L.) na atividade das enzimas peroxidase e polifenoloxidase. Utilizaram-se os seguintes tratamentos: 10 pulgões/planta; 30 pulgões/planta; 50 pulgões/planta e a testemunha (sem pulgões). A peroxidase apresentou atividade mais intensa em relação à polifenoloxidase. A maior atividade da peroxidase ocorreu quando se utilizaram 30 e 50 pulgões/planta. Já para a polifenoloxidase, não houve diferença na sua atividade entre as três densidades utilizadas.
\end{abstract}

Termos para indexação: Pulgão-verde, peroxidase, polifenoloxidase.

\begin{abstract}
It was investigated the effect of the population density of the greenbug Schizaphis graminum (RONDANI, 1852) on wheat plants (Triticum aestivum L.) on the activity of the enzymes peroxidase and polyphenoloxidase. The following treatments were used: 10, 30, 50 aphids/plant and the control (without aphids). The peroxidase showed higher activity than the polyphenoloxidase. The highest peroxidase's activity occurred when 30 and 50 aphids per plant were used. On the other hand, for polyphenoloxidase, there wasn't difference in the activity among the three densities used.
\end{abstract}

Index terms: Greenbug, peroxidase, polyphenoloxidase.

(Recebido para publicação em 26 de novembro de 2003 e aprovado em 26 de agosto de 2004)

O trigo (Triticum aestivum L.) é um importante cereal cultivado no Brasil e no mundo e sua produção mundial representa cerca de $30 \%$ da produção de cereais. Esse cereal fornece aproximadamente $20 \%$ das calorias ingeridas pela população, além de ser um dos alimentos mais importantes da cesta básica e componente essencial na alimentação humana. Apesar de sua importância, a produção brasileira de cerca de 4,5 milhões de toneladas na safra 2003 é incapaz de abastecer o mercado interno, que estima importar aproximadamente 6,5 milhões de toneladas na safra 2003/04 (AGRIANUAL, 2004). O pulgão-verde $S$ chizaphis graminum é uma das principais pragas do trigo, causando danos pela seiva extraída das plantas, injeção de fitotoxinas, transmissão de viroses e por sua grande capacidade de proliferação, podendo ocasionar até a morte das plantas (CRUZ et al., 1998).
Resistência induzida é um fenômeno que ocorre nas plantas em conseqüência das injúrias, danos ou estresses, que diminuem a preferência ou a performance do herbívoro (KARBAN e MYERS, 1989). Para o desencadeamento do processo de resistência induzida, é necessário um elicitor, que pode ser biótico, como o herbívoro (DIXON et al., 1994; DANGL, 1998). Entre os eventos relacionados à resistência induzida, destacase o aumento da atividade de enzimas relacionadas com a defesa das plantas, como a peroxidase e polifenoloxidase. A peroxidase (POX) está relacionada com a síntese de lignina e suberina, que aumentam a rigidez dos tecidos, e com a produção de quinonas e oxigênio ativo, que possuem propriedades antibióticas (GOODMAN et al., 1986; BOWLES, 1990; STOUT et al., 1994). A polifenoloxidase (PPO), além de estar envolvida no processo de lignificação, é também responsável pela catálise oxidativa de fenóis a o-quinonas, que se complexam

\footnotetext{
1. Aluno de Doutorado do Departamento de Entomologia da Universidade Federal de Lavras/UFLA - Caixa Postal 3037 - $37200-000$ - Lavras, MG, Fax: (035) 3829-1291.

2. Professor do Departamento de Entomologia/UFLA

3. Professor do Departamento de Química/UFLA.
} 
com proteínas, diminuindo a qualidade nutricional do alimento e dificultando a digestão protéica (FELTON e DUFFEY, 1990; FELTON et al., 1994; MOHAMMADI e KAZEMI, 2002).

Objetivou-se neste trabalho verificar o efeito da densidade do pulgão-verde em plantas de trigo na atividade das enzimas peroxidase e polifenoloxidase.

Este experimento foi conduzido na casa-devegetação do Departamento de Entomologia e no Laboratório de Bioquímica do Departamento de Química da Universidade Federal de Lavras. Utilizaram-se pulgões da criação de manutenção do Departamento de Entomologia, que se iniciou com indivíduos oriundos da Embrapa Milho e Sorgo em Sete Lagoas-MG. Esses pulgões foram mantidos em folhas de sorgo da cultivar BR85 em sala climatizada com temperatura de $26 \pm 2{ }^{\circ} \mathrm{C}$, umidade relativa de $70 \pm 10 \%$ e fotofase de 12 horas.

Inicialmente foram semeadas quatro sementes de trigo da variedade Embrapa 42 em cada vaso plástico com capacidade para $500 \mathrm{~mL}$. O substrato utilizado foi uma mistura de areia, terra de barranco e esterco, na proporção 1:1:1. Após a emergência das plântulas, foi feito o desbaste deixando-se apenas 1 plântula e foram colocadas gaiolas feitas de tecido tipo organza $(40 \times 40 \times 80 \mathrm{~cm})$. Aos 30 dias após a emergência, as plantas receberam os tratamentos: 1- testemunha (sem pulgões); 2- infestação com 10 pulgões/planta; 3- infestação com 30 pulgões/planta; 4- infestação com 50 pulgões/planta. Após 5 dias de infestação, foram determinadas as atividades da peroxidase e polifenoloxidase.

As folhas de trigo foram maceradas na presença de nitrogênio líquido com auxílio de almofariz e pistilo. Para obtenção do extrato enzimático, em 0,2 g de folha macerada, foram adicionados $10 \mathrm{~mL}$ de tampão fosfatopotássio 0,1 mol.L $\mathrm{L}^{-1}$ e $\mathrm{pH}$ 6.1. Após uma hora a $4^{\circ} \mathrm{C}$ com agitações periódicas, a solução foi centrifugada a 13000.g, por 15 minutos, a $4^{\circ} \mathrm{C}$. Os sobrenadantes (extratos enzimáticos) foram utilizados para a determinação da atividade enzimática. As atividades da POX e da PPO foram medidas espectrofotometricamente mediante aumento no $\mathrm{OD}_{470} / \mathrm{min} / \mathrm{g}$ e $\mathrm{OD}_{420} / \mathrm{min} / \mathrm{g}$, respectivamente, seguindo a metodologia adaptada de Silva (2002). A POX e a PPO utilizaram guaiacol $/ \mathrm{H}_{2} \mathrm{O}_{2}$ e catecol, respectivamente, como substrato. As leituras foram feitas a cada segundo, durante 2 minutos e as atividades foram expressas em unidade por grama de peso fresco (u/g). Uma unidade de atividade foi definida como o incremento de 0,1 unidade de absorbância por minuto nas condições do ensaio.

Foi utilizado o delineamento inteiramente casualizado com 8 repetições, sendo a parcela constituída por um vaso. Os dados obtidos foram submetidos à análise de variância e as médias, comparadas pelo teste de Tukey com 5\% de significância e, posteriormente, foi feita a análise de regressão.

Verificou-se que houve maior atividade da peroxidase e polifenoloxidase com o aumento da densidade do pulgão-verde (Figura 1). Notou-se ainda que a peroxidase teve uma resposta mais intensa em relação à polifenoloxidase.

A maior atividade da peroxidase foi observada quando se utilizaram 30 e 50 pulgões /planta (Tabela 1). Já para a polifenoloxidase, as densidades de 10, 30 e 50 pulgões foram semelhantes e significativamente maiores que a testemunha.

TABELA 1 - Atividade da peroxidase e da polifenoloxidase (média \pm erro-padrão) em função da densidade populacional do pulgão Schizaphis graminum em plantas de trigo.

\begin{tabular}{ccc}
\hline \multirow{2}{*}{ Tratamentos } & \multicolumn{2}{c}{$\begin{array}{c}\text { Atividade enzimática } \\
\text { (u/g peso fresco) }\end{array}$} \\
\cline { 2 - 3 } & Peroxidase & Polifenoloxidase \\
\hline Testemunha & $50 \pm 16,2 \mathrm{~b}$ & $11 \pm 1,5 \mathrm{~b}$ \\
10 pulgões & $51 \pm 6,7 \mathrm{~b}$ & $21 \pm 1,6 \mathrm{a}$ \\
30 pulgões & $108 \pm 16,0 \mathrm{a}$ & $23 \pm 2,4 \mathrm{a}$ \\
50 pulgões & $143 \pm 11,4 \mathrm{a}$ & $28 \pm 1,9 \mathrm{a}$ \\
\hline
\end{tabular}

As médias seguidas de mesma letra minúscula na coluna não diferem entre si pelo teste de Tukey com $5 \%$ de significância.

A herbivoria pode desencadear respostas de defesa nas plantas, como o aumento na atividade de enzimas oxidativas, sendo o aumento da atividade dessas enzimas a indicação de síntese de compostos de defesa da planta a agentes externos. Em estudos com plantas Solanum integrifolium Poir., pode-se verificar que a alimentação de Aphis gossypii Glover (Hemiptera: Aphididae) aumentou a atividade da peroxidase (OWUSU et al., 1994). Stout et al. (1998) verificaram que a alimentação do afídeo Macrosiphum euphorbiae (Thomas) (Hemiptera: Aphididae) em folhas de tomate também induziu a atividade da peroxidase. Jiang e Miles (1993) demonstraram que a indução da atividade da polifenoloxidase em tecidos de plantas de alfafa (Medicago sativa L.) pela alimentação do pulgão da alfafa Therioaphis trifolii Monell f. Maculata (Hemiptera: Aphididae). 


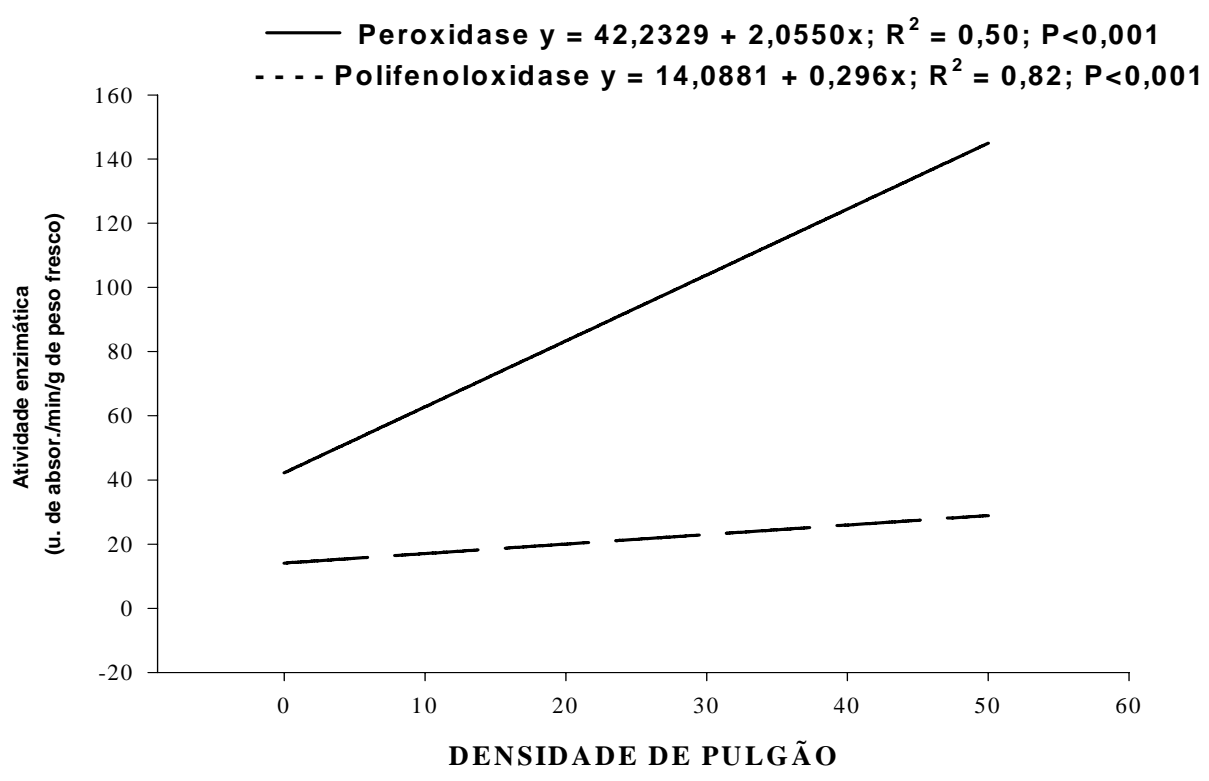

FIGURA 1 - Efeito da densidade populacional do pulgão-verde Schizaphis graminum na atividade das enzimas peroxidase e polifenoloxidase.

Conclui-se que a infestação das plantas com o pulgão-verde aumentou a atividade da peroxidase e da polifenoloxidase, significando que uma infestação inicial pode aumentar a resistência de plantas de trigo da variedade Embrapa-42.

\section{REFERÊNCIAS BIBLIOGRÁFICAS}

AGRIANUAL. Anuário da Agricultura Brasileira 2004. São Paulo: FNP Consultoria e Comércio, 2003. 496 p.

BOWLES, D. J. Defense-related proteins in higher plants. Annual Review of Biochemistry, Palo Alto, v. 59, p. 873-907, 1990.

CRUZ, I.; VENDRAMIN, J. D.; OLIVEIRA, A. C. Determinação do período de avaliação de não preferência de sorgo ao pulgão-verde, Schizaphis graminum (Rond.) (Homoptera: Aphididae). Anais da Sociedade Entomológica do Brasil, Piracicaba, v. 27, n. 2, p. 299-302, jun. 1998.

DANGL, J. L. Plants just say NO to pathogens. Nature, London, v. 394, n. 6393, p. 525-527, Aug. 1998.

DIXON, R. A.; HARRISON, M. J.; LAMB, C. J. Early events in the activation of plant defense responses. Annual Review of Phytopathology, Palo Alto, v. 32, p. 479-501, 1994.
FELTON, G. W.; DUFFEY, S. S. Inactivation of baculovirus by quinones formed in insect-damaged plant tissues. Journal of Chemical Ecology, New York, v. 16, n. 4, p. 1221-1236, Apr. 1990.

FELTON, G. W.; SUMMERS, C. B.; MUELLER, A. J. Oxidative responses in soybean foliage to herbivory by bean leaf beetle and three-cornered alfalfa hopper. Journal of Chemical Ecology, New York, v. 20, n. 3, p. 639-650, Mar. 1994.

GOODMAN, R. N.; KIRALY, Z.; WOOD, K. R. Secondary metabolite. In: GOODMAN, R. N. The Biochemistry and Physiology of Plant Disease. Missouri: University of Missouri, 1986. p. 211-224.

JIANG, Y.; MILES, P. W. Responses of a compatible Lucerne variety to attack by spotted alfalfa aphid: changes in the redox balance in affected tissues. Entomologia Experimentalis et Applicata, Dordrecht, v. 67, n. 3, p. 263-274, June 1993.

KARBAN, R.; MYERS, J. H. Induced plant responses to herbivory. Annual Review of Ecology and Systematics, Palo Alto, v. 20, p. 331-348, 1989. 
MOHAMMADI, M.; KAZEMI, H. Changes in peroxidase and polyphenol oxidase activies in susceptible and resistant wheat heads inoculated with Fusarium graminearum and induced resistance. Plant Science, Limerick, v. 162, n. 4, p. 491-498, Apr. 2002.

OWUSU, E. O. et al. Some biochemical changes in garden egg (Solanum integrifolium) Legon "18" due to feeding by Aphis gossypii (Homoptera: Aphididae). Phyton, Vicente Lopez, v. 55, n. 2. p. 147-152, 1994.
SILVA, L. H. C. P. Resistência sistêmica ativada pelo acibenzolar-s-metil contra doenças em tomateiro. 2002. 89 p. Dissertação (Mestrado em Fitopatologia) Universidade Federal de Lavras, Lavras, 2002.

STOUT, M. J.; WORKMAN, J.; DUFFEY, S. S. Differential induction of tomato foliar proteins by arthropod herbivores. Journal of Chemical Ecology, New York, v. 20, n. 10, p. 2575-2594, Oct. 1994.

STOUT, M. J. et al. Specificity of induced resistance in the tomato, Lycopersicon esculentum. Oecologia, Berlin, v. 113, n. 1, p. 74-81, 1998. 